\title{
Nocturnal electroencephalogram registrations in Type 1 (insulin-dependent) diabetic patients with hypoglycaemia
}

\author{
I. Bendtson ${ }^{1}$, J.Gade ${ }^{2}$, A.M. Rosenfalck ${ }^{1}$, C. E. Thomsen ${ }^{2}$, G. Wildschiødtz ${ }^{3}$ and C. Binder ${ }^{1}$ \\ ${ }^{1}$ Steno Memorial Hospital, Gentofte, ${ }^{2}$ Department of Medical Informatics and Image Analysis, Aalborg University, \\ ${ }^{3}$ Department of Clinical Neurophysiology, Copenhagen University Hospital, Gentofte, Denmark
}

\begin{abstract}
Summary. Eight Type 1 (insulin-dependent) diabetic patients with no diabetic complications were studied overnight for two consecutive and one subsequent night with continuous monitoring of electroencephalogram and serial hormone measurements. The aims were: 1 ) to evaluate the influence of spontaneous and insulin-induced hypoglycaemia on nocturnal electroencephalogram sleep-patterns and, 2) to evaluate counter-regulatory hormone responses. Spontaneous hypoglycaemia occurred on six nights ( $38 \%$ ) with blood glucose concentrations $<3.0 \mathrm{mmol} / \mathrm{l}$ and on four nights $<2.0 \mathrm{mmol} / \mathrm{l}$. All the patients experienced insulin-induced hypoglycaemia with a blood glucose nadir of 1.6 (range 1.4-1.9) $\mathrm{mmol} / \mathrm{l}$. The electroencephalogram was analysed by a new method developed for this purpose in contrast to the traditional definition of delta-, theta-, alpha- and beta-activity. The blood glucose concentration could be correlated to the rank of individual electroencephalogram-patterns during the whole night, and specific hypoglycaemic amplitude-frequency pat-
\end{abstract}

terns could be assigned. Three of the eight patients showed electroencephalogram changes at blood glucose levels below $2.0(1.6-2.0) \mathrm{mmol} / \mathrm{l}$. The electroencephalogram classes representing hypoglycaemic activity had peak frequencies at 4 and $6 \mathrm{~Hz}$, respectively, clearly different from the patients' delta- and theta-activity. The changes were not identical in each patient, however, they were reproducible in each patient. The changes were found equally in all regions of the brain. The three patients with electroencephalogram changes during nocturnal hypoglycaemia could only be separated from the other five patients by their impaired glucagon responses. Against this background the possibility of protection by glucagon, against neurophysiologic changes in the brain during hypoglycaemia may be considered.

Key words: Type 1 (insulin-dependent) diabetes mellitus, nocturnal hypoglycaemia, electroencephalogramregistrations, glucagon response.
Electroencephalographic (EEG) recordings from diabetic patients have shown that $31-80 \%$ of these patients had permanent EEG-changes, with the highest frequency in patients with recurrent episodes of severe hypoglycaemia $[1-3]$.

Induced hypoglycaemia (blood glucose concentration $<3.0 \mathrm{mmol} / \mathrm{l}$ ) in healthy subjects, showed reduced alpha activity and increased theta activity [4]. Similar changes were demonstrated in insulin-treated diabetic patients, with a blood glucose level $<2.0 \mathrm{mmol} / 1[5,6]$. A further decline in blood glucose led to accentuation of the EEGchanges [5]. The described EEG-changes are presumably a result of lack of fuel in the neurons since the EEG normalised after i.v. glucose administration. Similar changes occur during sleep in normal subjects, including a concomitant increase in delta-activity [7].

Nocturnal asymptomatic hypoglycaemia has been reported to occur in $27-56 \%$ of diabetic patients for a duration of 2-12 h during hospitalization [8-10]. According to the patients the nocturnal hypoglycaemia was asymptomatic. This could indicate that the blood glucose threshold for EEG-changes could be different during sleep compared to being awake.

In daytime studies on EEG activity during hypoglycaemia, all the patients showed EEG-changes [5, 6]. The long diabetes duration in all patients might suggest that these patients did not show a glucagon response to hypoglycaemia, as this has been stated almost as a rule [11-13].

In the present study we have evaluated EEG continuously and hormonal counter-regulation serially to nocturnal hypoglycaemia in eight Type 1 (insulin-dependent) diabetic patients.

\section{Patients and methods}

Eight Type 1 diabetic males participated in the study. They are all included in the Steno Memorial Prospective Diabetes Study [14]. Clinical characteristics of the patients are shown in Table 1 . No 


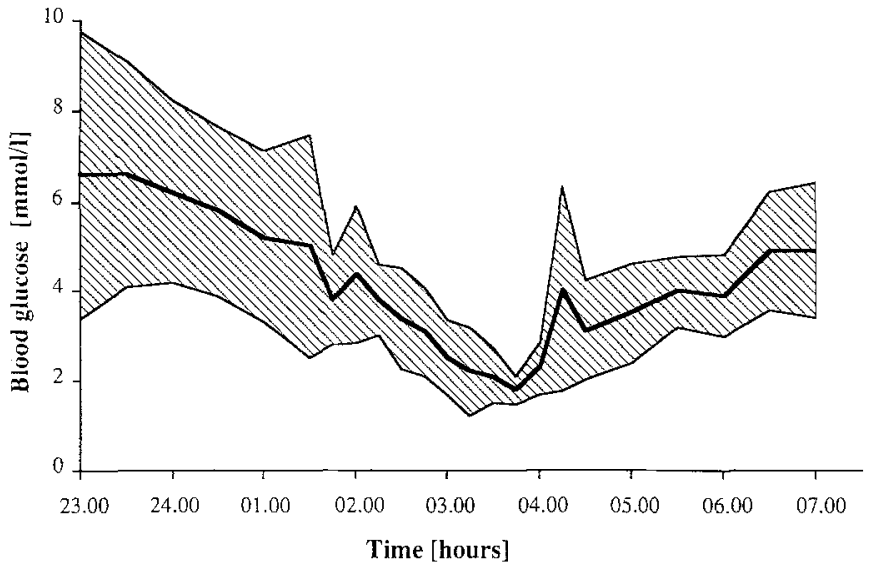

Fig. 1. Blood glucose level (mean) for all patients on nights with insulin-induced hypoglycaemia. The hatched area shows ranges (2 SD from mean values)

medication other than insulin was being taken. All the patients had urine albumin excretions $<30 \mathrm{mg} / 24 \mathrm{~h}$, normal blood pressure and normal ECG, no patient showed signs of retinopathy or neuropathy. None had any history of epilepsy or other neurological disturbances, including present or previous head injuries.

All the patients gave their informed consent. The study was approved by the regional ethics committee.

\section{Study design}

\section{Spontaneous hypoglycaemia/normoglycaemia}

The patients were admitted to the Department of Neurophysiology at 22.00 hours after a normal working day with no changes in diet, insulin dose or physical activity. No alcohol was consumed on the study days. Upon arrival they were placed on bed-rest, where they stayed until 07.00 hours the following morning. A heparinized cannula was inserted in an antecubital vein for blood sampling. Blood was drawn every $60 \mathrm{~min}$, and if the blood glucose level fell below $3.0 \mathrm{mmol} / \mathrm{l}$, the interval between measurements was reduced to $15 \mathrm{~min}$ until the blood glucose concentration again was stable above $4 \mathrm{mmol} / \mathrm{l}$.

For this part of the study patients were admitted to hospital on two consecutive nights. The patients were asked to report hypoglycaemic symptoms, and could be given glucose if requested.

\section{Insulin-induced hypoglycaemia}

The patients were admitted at 22.00 hours after a normal working day including usual diet and physical activity. Intermediate acting insulin was omitted before dinner and/or before bedtime. Upon arrival at the hospital two cannulas were inserted into contralateral antecubital veins; the cannula for blood sampling was heparinized and the other was kept patent with a $154 \mathrm{mmol} / 1 \mathrm{NaCl}$ infusion containing Velosulin Human $100 \mathrm{IU} / \mathrm{ml}$ (Novo Nordisk, Gentofte, Denmark). Insulin infusion was given by an insulin pump (Imed, Oxford, UK). The pump used a $60 \mathrm{ml}$ syringe containing: $57 \mathrm{ml}$ isotonic $\mathrm{NaCl}, 3 \mathrm{ml} \%$ human albumin and 15 IU insulin, equivalent to an insulin concentration of $0.25 \mathrm{IU} / \mathrm{ml}$. Infusion rates were dependent on the actual blood glucose concentration. The ideal was to have blood glucose stabilized at about $6 \mathrm{mmol} / \mathrm{luntil} 01.30$ hours, then toinduce hypoglycaemia by increasing the insulin infusion rate to about $4 \mathrm{IU} / \mathrm{h}$.

The blood glucose level should decrease to $2 \mathrm{mmol} / \mathrm{l}$ over $1 \mathrm{~h}$, and then be stabilized for around $1 \mathrm{~h}$ at $2 \mathrm{mmol} / \mathrm{l}$ or just below $2 \mathrm{mmol} / \mathrm{l}$. Thereafter $10 \mathrm{~g}$ glucose was injected i.v., (Fig. 1). Blood was drawn every 30 min during stabilization. From the time when the infusion rate was increased to cause hypoglycaemia blood was drawn every 15 min until the blood glucose level increased again and stabilized at about $4 \mathrm{mmol}$.

\section{Analytical methods}

Blood glucose concentrations were measured in duplicate: bedside with a oxidase method (Hypocount Mx-B, BM-Test-BG, Boehringer-Mannheim, Mannheim, FRG) and later with a dehydrogenase method (Cobas Mira, Hoffmann la Roche, Basel, Switzerland). Results from the Cobas-analysis are presented.

Blood for measurements of cortisol and growth hormone was centrifuged for $10 \mathrm{~min}$ and separated immediately. Serum samples were stored at $-20^{\circ} \mathrm{C}$. Growth hormone was measured by radioimmunoassay [15], cortisol by a commercial kit (Kingo Diagnostica, Copenhagen, Denmark). Samples for determinations of glucagon and catecholamines were treated and measured as described elsewhere $[15,16]$.

Significant increments in hormones were determined in accordance with Amiel et al. [17]. That is for epinephrine an increment of $75 \mathrm{ng} / \mathrm{l}=0.4 \mathrm{nmol} / \mathrm{l}$ above basal, for norepinephrine $50 \mathrm{ng} / \mathrm{l}$ $=0.3 \mathrm{nmol} / 1,7 \mu \mathrm{g} / \mathrm{l}$ for growth hormone and $7 \mathrm{ng} / \mathrm{l}=200 \mathrm{nmol} / \mathrm{l}$ for cortisol. For glucagon we have chosen pre-values $+2 \mathrm{SD}$ as significant increments. Patients with values below that are considered nonresponders.

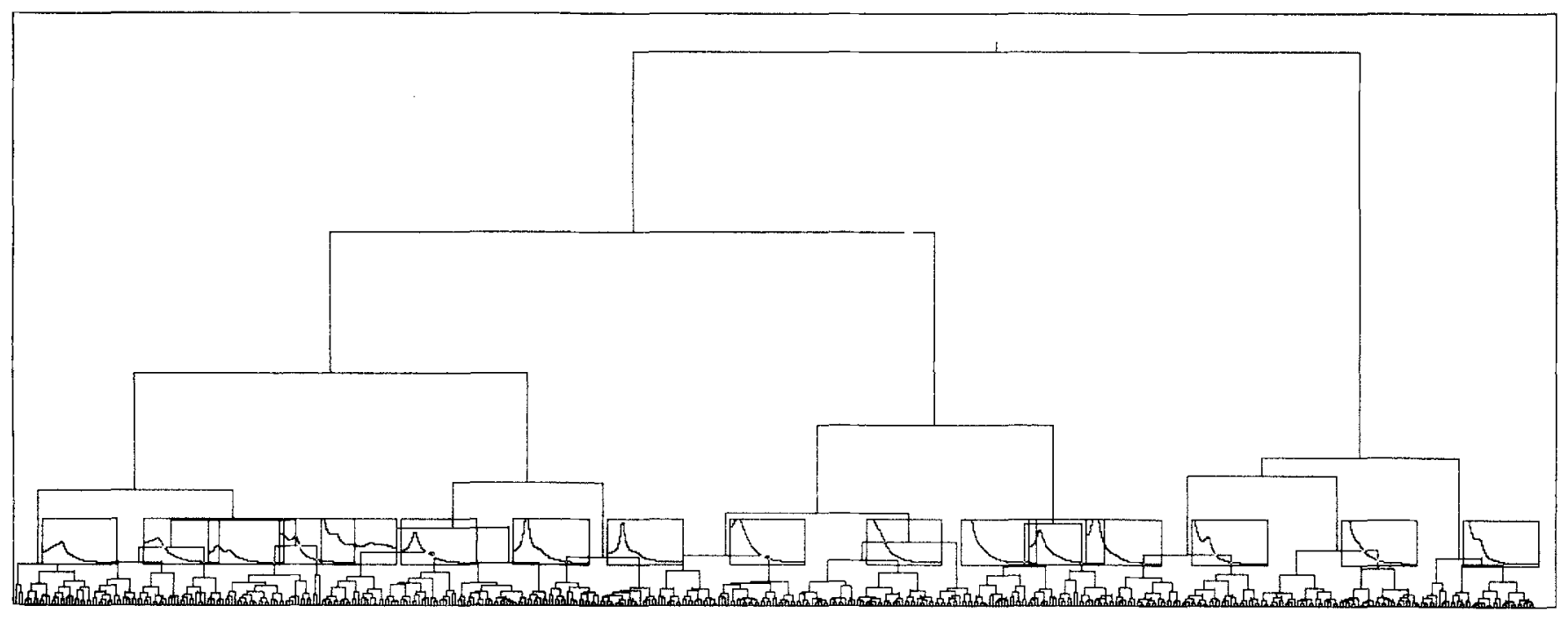

Fig. 2. The dendrogram shows how the learning set appears by hierarchical clustering. The branches at the bottom each represent one 2-s segment, while the root at the top represents the entire learning material, which is presented specifically in Figure 3 


\section{Registrations}

$E E G$. Bipolar EEG was registered continuously, on an electroencephalograph via surface electrodes placed over eight cerebral regions (F3, F4, C3, C4, T3, T4, O1, O2) and the references (A1, A2). Tracings used were: C4-A1, C3-A2, F4-C4, F3-C3, P4-O2, P3-O1, T4-T6, T3-T5.

$E C G$ (electrocardiography). Standard bipolar pre-cordial tracings were used.

EMG (electromyography). Submental chin tracings were used with pre-filled disposable electrodes.
AOG (actooculography). Eye movements were measured with a piezo-cheramic mechanical sensor (Siemens E232E, Siemens, Munich, FRG).

All signals were recorded and stored on a 14-channel video tape recorder (TEAC XR 510, Teac Corp., Tokyo, Japan). Due to the tape length the tape-recorder sets a maximum length of $8 \mathrm{~h}$ including calibration.

The signals were analysed off-line on a laboratory set-up using an Intel 310 computer system (Intel Corp., Santa Clara, Calif., USA). The computer performs multi-task real-time programs. It is equipped with analogue to digital converter ( 12 bit resolution in 8 channels) and a high resolution colour graphic display system
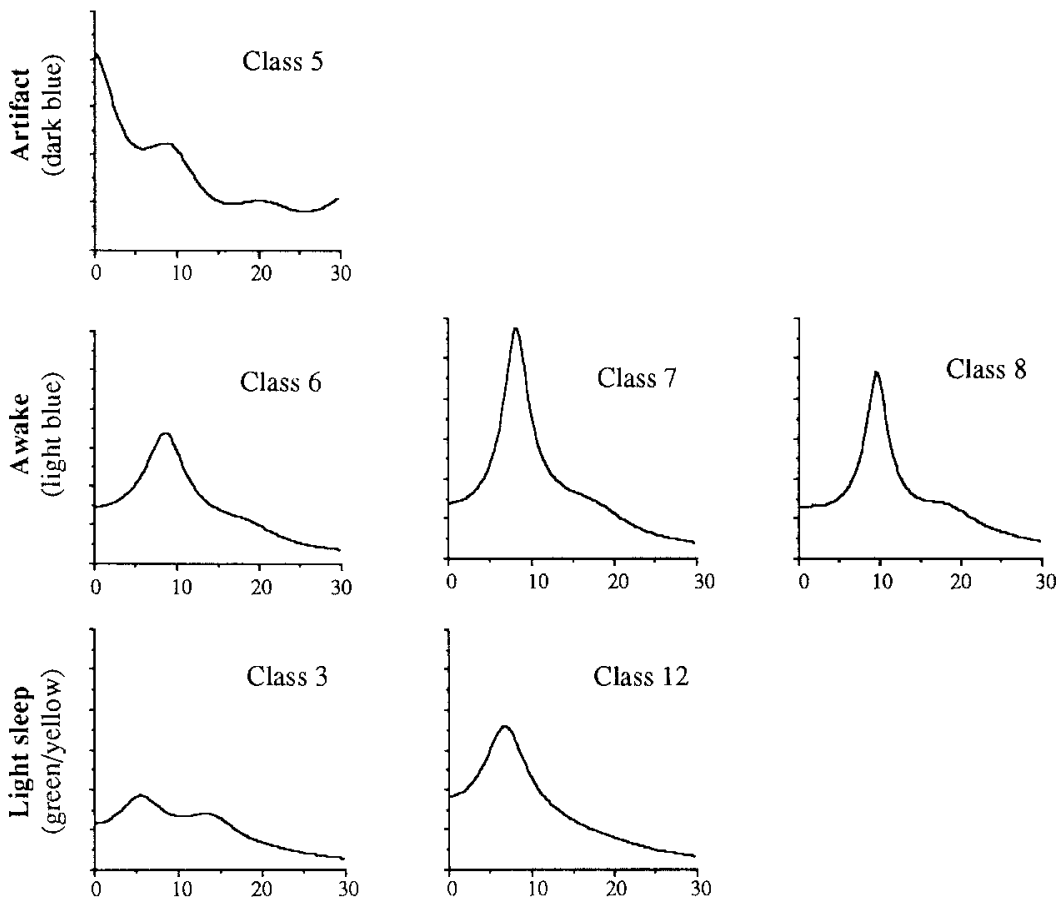

Class 12
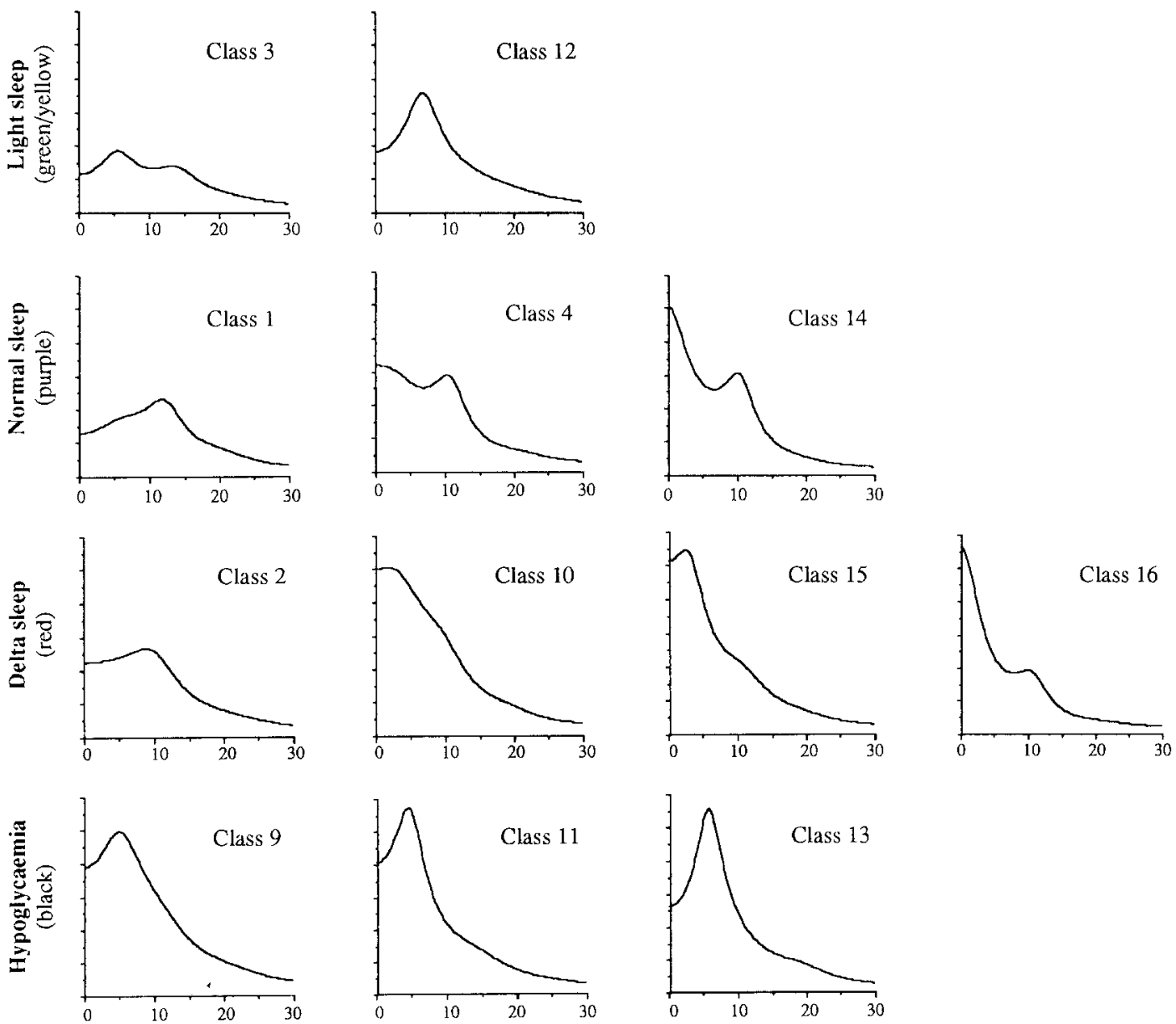

Fig. 3. Learning set as defined from the dendrogram (Figure 2). The electroencephalographic patterns in the learning set are assigned to the same colour code for similar brain states for patient 4 . The colours are shown in Figure 4 
( $1024 \times 512$ pixels and 256 programmable colours). Hardcopies of the displayed parameters were made on an HP Paint Jet Colour Graphics Printer (Hewlett-Packard, San Diego, Calif., USA).

The EEG-signals were sampled at $100 \mathrm{~Hz}$ and pre-emphasized by a first order $25 \mathrm{~Hz}$ high-pass filter. The EEG was divided in 2-s segments. Information about amplitude and spectral content of the EEG were extracted from each segment. Pattern recognition was then performed using a probabilistic classifier (Bayes decision theory) [18]. The classifier used a learning set of patterns defined for each patient based on a spontaneous hypoglycaemic night if present, or a night with insulin-induced hypoglycaemia. From these nights learning material covering the whole night, but concentrated on the hypoglycaemic periods, were selected. By hierarchical clustering the segments were merged, ending up with one average segment for the selected material. The clustering is represented graphically in a dendrogram (Fig. 2). The branches at the bottom represent one 2-s segment, while the root at the top represents the entire learning material. To define the learning set, the dendrogram was cut near the top where 15-17 patterns were left, these patterns were used for classification of the EEG for the whole night.

The result of the analysis was presented in a class probability histogram where each line represents the class profile, that is the relative occurrence of the classes during the last five segments $(10 \mathrm{~s})$. The class probability histogram was filtered with a low pass filter to obtain an easier interpretation by smoothing of the histogram. The classes in the learning set were assigned to the same colour code for similar brain states, as shown in Figure 3 .

The blood glucose concentration was correlated to the rank of the individual EEG-classes during a whole hypoglycaemic night. If the rank of a class was increasing with decreasing blood glucose the class was assigned to the hypoglycaemia activity (black). The rest of the classes were assigned to the activities: artifact or movements (dark blue), awake (light blue), light sleep (green/yellow), normal sleep (purple) and deep sleep (red) according to knowledge of sleep analysis [7, 19], (Fig. 3).

\section{Statistical analysis}

Values are mean and (ranges). Paired Student's $t$-test and Wilcoxon rank sum test were used for significance tests, $p<0.05$ is considered statistically significant. Correlation coefficients were calculated by simple regression analysis.

\section{Results}

Spontaneous hypoglycaemia occurred on six nights with blood glucose levels $<3 \mathrm{mmol} / 1$, on four nights the blood glucose values were $<2 \mathrm{mmol} / \mathrm{l}$, exact values and durations are shown in Table 2. On two occasions with patient 4 , i.v. glucose was administered after about $1 \mathrm{~h}$ of hypoglycaemia with blood glucose level below $2 \mathrm{mmol} / \mathrm{l}$, due to the clinical observation of the patient being in a preexiteric state with heavily increased muscle tone.

Insulin-induced hypoglycaemic nights: Mean blood glucose values and standard deviations are shown in Figure 1. The blood glucose nadir was 1.6 (range $1.4-1.9$ ) $\mathrm{mmol} / \mathrm{l}$, (Table 2) nadir was reached between 03.00 and 03.45 hours.

Table 1. Clinical characteristics of the patients studied

\begin{tabular}{|c|c|c|c|c|c|c|c|}
\hline Patient & $\begin{array}{l}\text { Age } \\
\text { [years] }\end{array}$ & $\begin{array}{l}\text { Diabetes } \\
\text { duration } \\
\text { [years] }\end{array}$ & $\begin{array}{l}\text { Insulin } \\
\text { injections/day } \\
\text { [no.] }\end{array}$ & $\begin{array}{l}\text { Insulin doses } \\
{[\mathrm{IU} / \mathrm{kg}]}\end{array}$ & $\begin{array}{l}\mathrm{HbA}_{\mathrm{lc}} \\
{[\%]}\end{array}$ & $\begin{array}{l}\text { C-peptide } \\
\text { [nmol/1] }\end{array}$ & $\begin{array}{l}\text { Antibodies } \\
{[\%]}\end{array}$ \\
\hline 1 & 22 & 9 & 4 & 0.9 & 7.5 & 0.00 & 1.1 \\
\hline 3 & 43 & 3 & 2 & 0.5 & 9.1 & 0.00 & 0.0 \\
\hline 4 & 36 & 6 & 3 & 0.7 & 7.7 & 0.00 & 0.0 \\
\hline 5 & 26 & 8 & 2 & 0.4 & 7.5 & 0.06 & 0.0 \\
\hline 8 & 26 & 10 & 3 & 0.6 & 8.5 & 0.00 & 0.0 \\
\hline Mean & 31 & 7 & & 0.6 & 8.2 & 0.02 & 0.2 \\
\hline
\end{tabular}

Table 2. Hypoglycaemic episodes experienced by the patients

\begin{tabular}{|c|c|c|c|c|c|c|}
\hline & \multirow[t]{2}{*}{ Patient } & \multirow{2}{*}{$\begin{array}{l}\text { Blood glucose } \\
\text { nadir [mmol/l] }\end{array}$} & \multicolumn{2}{|c|}{ Duration [min] } & \multirow{2}{*}{$\begin{array}{l}\text { EEG- } \\
\text { changes }\end{array}$} & \multirow{2}{*}{$\begin{array}{l}\text { Glucagon- } \\
\text { response }\end{array}$} \\
\hline & & & $<3 \mathrm{mmol} / \mathrm{l}$ & $<2 \mathrm{mmol} / \mathrm{l}$ & & \\
\hline Spontaneous hypoglycaemia & $\begin{array}{l}1 \\
2 \\
4 \\
4 \\
7 \\
8\end{array}$ & $\begin{array}{l}1.7 \\
2.4 \\
1.8 \\
1.7 \\
2.8 \\
1.9\end{array}$ & $\begin{array}{l}240 \\
120 \\
160 \\
360 \\
300 \\
150\end{array}$ & $\begin{array}{c}120 \\
0 \\
75^{\mathrm{a}} \\
60^{\mathrm{a}} \\
0 \\
30\end{array}$ & $\begin{array}{l}\text { yes } \\
\text { no } \\
\text { yes } \\
\text { yes } \\
\text { no } \\
\text { yes }\end{array}$ & $\begin{array}{l}\text { N.M. } \\
\text { N.M. } \\
\text { N.M. } \\
\text { N.M. } \\
\text { N.M. } \\
\text { N.M. }\end{array}$ \\
\hline Insulin-induced hypoglycaemia & $\begin{array}{l}1 \\
2 \\
3 \\
4 \\
5 \\
6 \\
8\end{array}$ & $\begin{array}{l}1.9 \\
1.4 \\
1.6 \\
1.7 \\
1.4 \\
1.6 \\
1.4\end{array}$ & $\begin{array}{r}105 \\
135 \\
180 \\
150 \\
120 \\
90 \\
120\end{array}$ & $\begin{array}{l}30 \\
30 \\
60 \\
60 \\
60 \\
30 \\
60\end{array}$ & $\begin{array}{l}\text { yes } \\
\text { no } \\
\text { no } \\
\text { yes } \\
\text { no } \\
\text { no } \\
\text { yes }\end{array}$ & $\begin{array}{r}7 \\
50 \\
35 \\
-10 \\
52 \\
42 \\
15\end{array}$ \\
\hline
\end{tabular}

a Intravenous glucose administered

N.M., Not measured serially, the intervals were $60 \mathrm{~min}$ 


\section{EEG-registrations}

Three of the patients showed EEG-changes at blood glucose levels below $2.0(1.6-2.0) \mathrm{mmol} / \mathrm{l}$. The EEG classes representing hypoglycaemic activity were not identical. In two patients the hypoglycaemic classes had peak frequency of $6 \mathrm{~Hz}$ and the third patient had peak frequency of $4 \mathrm{~Hz}$. The assigned classes are shown for patient 4 in Figure 3.

The hypoglycaemic classes were reproducible in the patients, when the blood glucose level was below $2.0 \mathrm{mmol} / \mathrm{l}$ irrespective of whether the low glucose was due to spontaneous or i.v.-induced hypoglycaemia, the changes were found equally in all brain regions (Fig. 4).

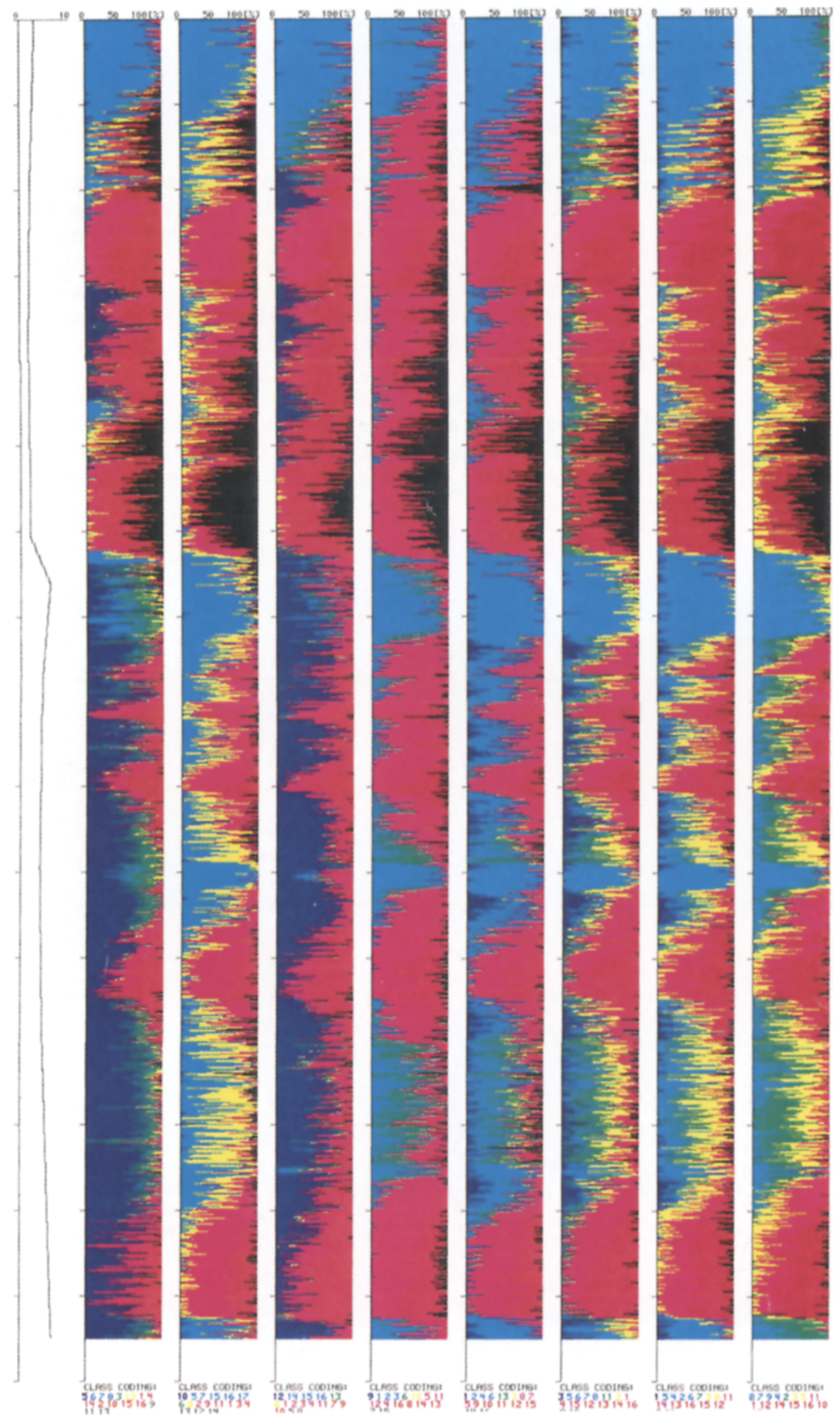

Fig.4. Electroencephalogram (EEG) for patient 4 on a night with spontaneous hypoglycaemia. The upper eight panels show the different tracings of the EEG, from top to bottom: temporal T3-T5 and T4-T6, parietal-occipital P3-O1 and $\mathrm{P} 4-\mathrm{O} 3$, frontal-central $\mathrm{F} 3-\mathrm{C} 3$ and $\mathrm{F} 4-\mathrm{C} 4$ and centrally $\mathrm{C} 3-\mathrm{A} 2$ and $\mathrm{C} 4-\mathrm{A} 1$. The colours are assigned from the learning set shown in Figure 3. The blood glucose level is shown underneath. At the time where the black, hypoglycaemic EEG pattern disappears, i.v. glucose was administered 
When the blood glucose level was increased by i. v. glucose the specific hypoglycaemic classes disappeared instantly (Fig. 4).

In the other five patients no correlation was found between blood glucose concentration and rank of classes, even at blood glucose levels lower than 1.6 (nadir 1.4) $\mathrm{mmol} / \mathrm{l}$.

\section{Counter-regulatory hormones}

In response to hypoglycaemia all the patients showed significant increments in all counter-regulatory hormones except for glucagon. Basal and peak values of the hormones for induced-hypoglycaemic nights are shown in Table 3.

Two of the patients showed no glucagon response at all, and another had a non-significant increment, (Fig. 5). The blood glucose nadir in these three patients did not differ from that in the other patients. Likewise, there was no difference between these three and the other patients in the response of the other hormones measured. As shown in Table 2 the three patients showing no glucagon response were the only patients with EEG-changes during hypoglycaemia. Their diabetes duration, metabolic control $\left(\mathrm{Hb}_{\mathrm{lc}}\right)$, insulin dose, insulin regimen and ages did not differ from the other patients (Table 1).

None of the patients complained of subjective hypoglycaemia, either during the night or in the morning, in spite of profuse sweating and increased muscle tone in the upper extremities during hypoglycaemia. All showed an increased heart rate during the hypoglycaemic episodes.

\section{Glucagon-infusions}

To test our findings we subsequently infused glucagon to two of the three non-responders. During hypoglycaemia, performed according to the second part of the protocol, we infused glucagon at $0.0167 \mathrm{mg} / \mathrm{h}$ concomitant with an increase in insulin-infusion rate in order to keep the blood glucose concentration below $2 \mathrm{mmol} / \mathrm{l}$. During this procedure the plasma-glucagon raised from $30 \mathrm{ng} / \mathrm{l}$ to $215 \mathrm{ng} / \mathrm{l}$, while the blood glucose level remained less than $2 \mathrm{mmol} / 1$. During hypoglycaemia, prior to the increased glucagon level, the EEG-changes previously seen were present; however, these changes disappeared when the glucagon

Table 3. Counter-regulatory hormones for all patients on nights with insulin-induced hypoglycaemia

\begin{tabular}{llclcl}
\hline Hormone & & Basal & \multicolumn{3}{c}{ Peak } \\
\hline Epinephrine & {$[\mu \mathrm{g} / \mathrm{l}]$} & 0.08 & $(0.04)$ & 0.43 & $(0.30)$ \\
Norepinephrine & {$[\mu \mathrm{g} / \mathrm{l}]$} & 0.35 & $(0.20)$ & 0.57 & $(0.40)$ \\
Cortisol & {$[\mathrm{nmol} / 1]$} & 72.0 & $(45.0)$ & 743.0 & $(171.0)$ \\
Growth hormone & {$[\mu \mathrm{g} / 1]$} & 2.4 & $(0.60)$ & 11.1 & $(5.6)$ \\
Glucagon & {$[\mathrm{ng} / 1]$} & 18.0 & $(10.6)$ & 44.7 & $(27.0)$ \\
responders & & 22.3 & $(14.0)$ & 62.8 & $(20.0)$ \\
non-responders & 14.7 & $(2.0)$ & 20.7 & $(6.0)$ \\
\hline
\end{tabular}

Values are mean and (SD)

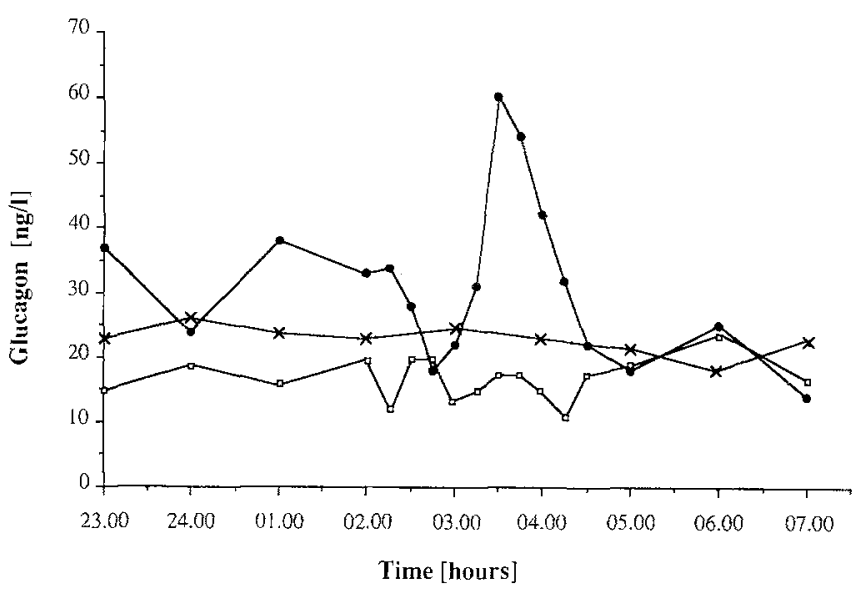

Fig.5. Plasma glucagon levels. $\times---x$ indicates normoglycaemic nights. - $\bullet$ The five patients with sufficient response to glucagon during hypoglycaemia. $\square \cdots \square$ The three non-responding patients' glucagon levels. Values are mean

levels were increased without concomitant increase in the blood glucose level.

\section{Discussion}

The present study shows that some, but not all, diabetic patients develop specific EEG-changes during nocturnal hypoglycaemia. The only parameter, that separated the patients with EEG-changes from those without, was their impaired glucagon response to hypoglycaemia. None of the studies published have shown both counter-regulatory hormone responses and EEG registrations during hypoglycaemia [5, 6]. However, all the patients in these studies had a longer diabetes duration, which might indicate that they were without glucagon response to hypoglycaemia, as this has been shown to decrease and vanish in the early years after onset of diabetes $[11,12]$. Thus, in accordance with our findings, the patients in the studies of Pramming [5] and Tallroth [6] should develop the EEG-changes during hypoglycaemia due to their suspected impaired glucagon response.

The EEG-changes shown in this study, were similar to those found during daytime - that is an increase in deltaand theta-activity. The present data shows specific activity for hypoglycaemia. The activities had peak frequency at 4 and $6 \mathrm{~Hz}$, specific for each patient and different from their sleep derived delta- and theta-activity. During the daytime a concomitant decrease in alpha-activity was observed $[5,6]$. While asleep the decrease in alpha-activity has already occurred due to the sleep.

Concomitant with the development of the detection method, we have tested the recordings used in the present study with a polygraphic sleep analyser. The traditional sleep analysis showed a tendency to prolongation of the two first sleep-cycles on nights when hypoglycaemia occurred. The prolongation was equally distributed at all sleep stages. The sleep efficiency, that is actual sleep time as percentage of total time spent in bed, was about $90 \%$, which is normal, without statistical differences between 
hypoglycaemic and normoglycaemic nights. Sleep was initiated 5-15 min after the recordings were started. The traditional sleep analysis was insufficient to describe the dynamics of the activities in the EEG during hypoglycaemia [20]. The hypoglycaemic patterns could be detected during any sleep stage, even during deep sleep (delta- and theta-activities, $0.5-4$ and $4-8 \mathrm{~Hz}$ frequencies), by the method used in the present study. In contrast to the findings during daytime, we could not find any topical differences in the EEG-changes. This might be due to the sleep in that the major topical difference in daytime was the reduction in alpha-activity that was found to be most prominent in the frontal regions [5, 6].

The threshold in blood glucose for EEG-changes was the same as shown during daytime wakefulness $[5,6]$, suggesting that the brain has the same sensitivity to hypoglycaemia during sleep. However, five out of eight patients did not develop any EEG-changes despite blood glucose levels far below $2.0 \mathrm{mmol} / \mathrm{l}$. These patients might be protected against the EEG-changes by glucagon release. This speculation is based upon the observation in the patients without endogenous glucagon response to hypoglycaemia, in whom the EEG-changes vanished after i.v. glucagon without a concomitant increase in blood glucose concentration. This phenomenon needs further investigation. The antecedent glycaemic level might influence the threshold for the EEG-changes as it has been shown to influence the threshold for hormonal counter-regulation and onset of symptoms [17]. The patients with EEGchanges in the present study were quite well controlled, $\mathrm{HbA}_{1 \mathrm{c}} 7.5,7.7$ and $8.5 \%$, respectively, (normal range $4.3-6.4 \%$ ). The group without EEG-changes had greater variation in metabolic control $\left(\mathrm{HbA}_{1 c}: 6.5-10.1 \%\right)$, their blood glucose nadirs were lower, however, they still did not develop EEG-changes. Thus, from the present study and compared to the daytime studies $[5,6]$ it seems that the threshold for EEG-changes is unrelated to metabolic control. One unanswered question is why patients do not wake up during nocturnal hypoglycaemia. The hormonal counter-regulation is not significantly lower than during daytime hypoglycaemia. All the patients showed signs of hypoglycaemia such as profuse sweating and increased muscle tone, but no patient awoke irrespective of the presence or absence of EEG-changes and none complained of symptoms the following morning. The present study showed the same high frequency, $38 \%$, of spontaneous asymptomatic nocturnal hypoglycaemia, as has been shown in previous studies [8-10].

In conclusion nocturnal asymptomatic hypoglycaemia was found with the same high frequency as previously. Some, but not all patients, showed specific EEG-changes during hypoglycaemia. The threshold and the changes found were the same as during daytime. Patients with EEG-changes showed no glucagon response, as the only parameter measured and observed, that separated these patients from the others, who all had significant glucagon responses. This leads us to consider, whether glucagon, might partially protect the brain against neurophysiological changes during hypoglycaemia.

\section{References}

1. Greenblatt M, Murray J, Root HF (1946) Electroencephalographic studies in diabetes mellitus. N Engl J Med 234: 119-121

2. Fabrykant M (1953) Further studies on electrocerebral dysfunction and the use of anticonvulsants in labile diabetics. Ann Intern Med 38: 814-823

3. Haumont D, Dorchy H, Pelc S (1979) EEG-abnormalities in diabetic children. Clin Pediatr 18: 750-753

4. Davis PA (1943) Effect on the electroencephalogram of changing the blood sugar level. Arch Neurol Psychiatr 49: 186-194

5. Pramming S, Thorsteinsson B, Stigsby B, Binder C (1988) Glycaemic thresholds for changes in electroencephalograms during hypoglycaemia in patients with insulin dependent diabetes. $\mathrm{Br}$ Med J 296: 665-667

6. Tallroth G, Lindgren M, Stenberg G, Rosen I, Agardh C-D (1990) Neurophysiological changes during insulin-induced hypoglycaemia and in the recovery period following glucose infusion in Type 1 (insulin-dependent) diabetes mellitus and in normal man. Diabetologia 33: 319-323

7. Oswald I (1987) The normal record of sleep. In: Halliday BG, Butler SR, Paul R (eds) A textbook of clinical neurophysiology. John Wiley \& Sons, New York, pp 173-185

8. Gale EAM, Tattersall RB (1979) Unrecognized nocturnal hypoglycaemia in insulin treated diabetics. Lancet I: 1049-1052

9. Pramming S, Thorsteinsson B, Bendtson I, Ronn B, Binder C (1985) Nocturnal hypoglycaemia in patients receiving conventional treatment with insulin. Br Med J 291:376-379

10. Bendtson I, Kverneland A, Pramming S, Binder C (1988) Incidence of nocturnal hypoglycaemia in insulin dependent diabetic patients on intensive therapy. Acta Med Scand 223: 543

11. Bolli G, De Feo P, Compagnucci P et al. (1983) Abnormal glucose counterregulation in insulin-dependent diabetes mellitus. Diabetes 32: 134-141

12. Cryer P, Gerich J (1985) Glucose counterregulation, hypoglycaemia and intensive therapy of diabetes mellitus. N Engl $J$ Med 313:232-241

13. Hirsch IB, Smith LJ, Havlin CE, Shah SD, Clutter WE, Cryer P (1990) Failure of nocturnal hypoglycaemia to cause daytime hyperglycaemia in patients with IDDM. Diab Care 13: 133-142

14. Agner T, Damm P, Binder C (1987) Remission in IDDM: prospective study of basal C-peptide and insulin dose in 268 consecutive patients. Diab Care 10: 164-169

15. Ørskov H, Thomsen HG, Yde H (1968) Wick chromatography for rapid and reliable immunoassay of insulin, glucagon and growth hormone. Nature 219: 193-195

16. Hjemdahl P, Daleskog N, Kahan T (1979) Determinations of plasma catecholamines by high performance liquid chromatography with electrochemical detection, comparison with a radioimmuno-assay. Life Sci 25: 131-138

17. Amiel SA, Tamborlane W, Simonson D, Sherwin R (1987) Defective glucose counterregulation after strict metabolic control of insulin-dependent diabetes mellitus. N Engl J Med 316: 1376

18. Duda RO, Hart PE (1983) Pattern recognition and scene analysis. John Wiley \& Sons, New York

19. Rechtschaffen A, Kales A (1968) A manual of standardized terminology, techniques and scoring systems for sleep stages of human subjects. US Government Printing office, Washington

20. Bendtson I, Gade J, Wildschiødtz G, Rosenfalck A, Binder C (1990) Non-invasive detection of nocturnal hypoglycaemia in Type 1 diabetic patients. Diabetologia 33: A121 (Abstract)

Received: 5 April 1991

and in revised form: 10 July 1991

Dr. I.Bendtson

Steno Memorial Hospital

Niels Steensensvej 2

DK-2820 Gentofte/Denmark 